\title{
Application of Rasch Model on Resilience in Higher Education: An Examination of Validity and Reliability of Malaysian Academician Happiness Index (MAHI)
}

\author{
Khadijah Alavi ${ }^{1}$, Khairunesa Isa $^{2} \&$ Sarala Thulasi Palpanadan ${ }^{3}$ \\ ${ }^{1}$ Faculty of Social Sciences and Humanities, Universiti Kebangsaan Malaysia, 43600 UKM, 43600 Bangi, Selangor \\ ${ }^{2}$ Department of Social Science, Universiti Tun Hussein Onn Malaysia, 86400, Parit Raja, Batu pahat, Johor, \\ Malaysia \\ ${ }^{3}$ Department of English Language and Linguistics, Universiti Tun Hussein Onn Malaysia, 86400, Parit Raja, Batu \\ pahat, Johor, Malaysia \\ Correspondence: Khairunesa Isa, Department of Social Science, Universiti Tun Hussein Onn Malaysia, 86400, Parit \\ Raja, Batu pahat, Johor, Malaysia.
}

Received: April 26, 2020

Accepted: June 23, 2020

Online Published: June 25, 2020

doi:10.5430/ijhe.v9n4p261

URL: https://doi.org/10.5430/ijhe.v9n4p261

\begin{abstract}
This preliminary study was conducted to examine and verify the validity and reliability of the instrument on the Malaysian Academician Happiness Index (MAHI) on resilience. MAHI could be seen as a tool to measure the level of happiness and stress of academicians before determining how resilient the academicians were. Resilience can be defined as a mental ability of a person to recover quickly from illness or depression. MAHI instrument consisted of 66 items. The instrument was distributed to 40 academicians from three groups of universities which were the Focus University, Comprehensive University and Research University is using a survey technique. The instrument was developed to measure three main constructs which were the organization, individual and social that would affect the happiness and stress levels of academicians. This preliminary study employed the Rasch Measurement Model uses Winsteps software version 3.69.1.11. to examine the validity and reliability of the items. The results of the analysis of the MAHI instrument showed that the item reliability was 0.87 , person reliability was 0.83 and value of Alpha Cronbach was 0.84 . Meanwhile, misfit analysis showed that only there was one item with 1.46 logit that could be considered for dropping or needed improvement. Therefore, it highlighted that most of the items met the constructs' need and can be used as a measurement indicator of MAHI. The implication of this instrument can help Malaysian academicians to be more resilient in facing challenges in the future.
\end{abstract}

Keywords: academician happiness index, resilience, Islamic overview, public university, MAHI

\section{Introduction}

Academicians are the ones who are responsible to educate students who are characterized by the development of digitization and globalization. Academicians need to face daily challenges during teaching and learning process dealing with the complexity of students' attitude and other tasks to ensure that the students are marketable. In the era of globalization and Revolution Industrial 4.0, an academician is expected to exhibit new skill and be more aggressive that could fit the current market demand such as being an expert in using technology, collaboration and problem solving.

As an academician, there are several key performance indicators that need to be done yearly, including teaching and learning, writing, publishing, administrating, doing research and consultation and being involved in community service as well. Each event indicator has a different weighting, but academicians need to put their full effort to achieve all the indicators not only for the promotion but also for personal development (Hargreaves \& Fink, 2006). In order to achieve the key performance indicator, academicians will face many challenging and unpredictable situations that may affect their emotions and physical health.

According to Higher Education Statistics Agency (HESA) which is an agency in UK higher education data, the challenges faced by lecturers include obtaining funding for research, increasing number of students at postgraduate level, balancing research and teaching, shifting to e-Learning, taking work home and increasing the need to have a 
teaching qualification (Liaison, 2020). In line with this data, Maria at al. (2015), reported that there are positive and negative career shocks that have been faced by academicians. The common positive career shocks included publishing papers in top tier journals, receiving teaching awards and being elected to serve in leadership roles in academic professionals. Meanwhile, the three negative shocks that have been faced by the academicians were experiencing negative political incidents within the department, having difficulties obtaining jobs and being in the department that had been affected by significant organisational changes.

The way the academicians accept and experience the situation depend on their resilience or ability to cope with the pressure because there are some studies that show academics are exposed to workplace unhappiness which ultimately affects their mental health. Resilience can be defined as the process of effectively negotiating, adapting or managing substantial sources of stress (Hobfoll et al. 2003) and may enable academicians to control and have impact on their changing work environment successfully (Windle, 2011). Henderson and Milstein (1996) added that resilience is the capacity to spring back, rebound, successfully adapt in the face of adversity, and develop social, academic and vocational competence despite exposure to severe stress that is inherent in today's world.

According to Fouche and Van Der Vyver (2017), work engagement and job crafting fully mediated the relationship between meaningful work and educators' resilience and their study concluded that meaningful work by revealing a mediating mechanism through which educators' experience of meaningful work affects their resilience. Employees may face either happiness or stress environment in their workplace depending on how the situation occurs to get that experience. While Margaret et al., (2015) in her study found that the best way to cope with resilience is by having matured. In the meantime, Leahy (2012) stated that role of colleagues, student, family, friends and principal or management are important in developing and sustaining lecturers' resilience.

In the context of the university, there are a lot of factors that can contribute to the happiness and stress levels among the academicians. It is important for the lecturers know how to handle the situation which can lead them to be happy or stressed because the definition of happiness and stress are different based on individual perception. The identification of the factors that will affect lecturers' happiness will help them manage their emotions to face the situations better. Therefore, this study tries to identify the significant items which are reliable that can be used to measure the happiness and stress levels of the lecturers in Malaysia.

\subsection{Malaysian Academician Happiness Indicator (MAHI)}

Happiness in the workplace refers to the feeling that employees truly love what they serve and the things that make them to be proud of themselves. Many previous researchers found that happiness in the workplace will affect employee lifestyle, performance, and individual stress (Fisher, 2010; Wulandari and Widyastuti, 2004; Yang and Li, 2011). According to Tharek (2011), some of the stress cases among university lecturers are caused by workload, role conflict and relationship with others. In addition, the study conducted by Wulandari and Widyastuti (2004) found that the relationships among individuals will influence the employee happiness levels. Hoesni and Zakaria (2019) happiness in a marriage of individuals to perform their functions, roles in life and could handle multiple responsibilities within family and their colleagues.

Aziz (2014) found that academician personality such as extraversion, neuroticism, agreeableness, and conscientiousness are the traits that influence the level of lecturer happiness. Besides, demographic factors such as age, salary and marriage status will affect the happiness among the lecturers at a low level. Other than that, organizational elements and employees' psychology such as workload, work environment (Zafir and Fazilah, 2010), organization culture, job specification, job satisfaction, turnover, employee commitment, and appreciation also have been found as significant factors affecting employee happiness at work place. In line with that, Yang and Li (2011) stated that the significant indicators to measure employee happiness at workplace are their physical and mental wellness. It is because in order to understand the subject of well-being one must be worried about many facets including the cognitive and emotion of the individual and group.

Referring to the Model of Happiness by Happiness Inventory Manual, there are three domains in the circle of ecology that could affect happiness in the organization which are individual, organization and family or social. Each domain has several items which have different influence to the happiness. In the Happiness Index among the university staff research, Isa et al., (2019) found three domains that have contributions towards the staff happiness and stress levels which are the social factor, organization factor and individual factor. In this study, the relationship between family members and friends, which is the social sub domain, has a huge contribution towards the happiness level. In the context of organizational domain, the working environment and organization support have been identified as the contributing factors towards the happiness even at low level. The study conducted by Isa et al. (2019), supported Ramlee (2015) which found that workload, interpersonal relationship, time limitation, sources, and 
student attitude will affect lecturers' stress level. According to Desa et al. (2014) neurotic individual has the tendency to experience negative emotions such as emotional instability, depressive mood, nervous breakdown, hyper reactivity, over anxiousness and this tendency will acts toward job stress. The results suggest that lecturers that are also working as administrators need to know their personality characteristics so that they will be aware of their own personal dispositions that may reduce or aggravate stress. Emotional intelligence levels of 108 lecturers are at moderate level and contribute to lecturer's job satisfaction. The results of this study are expected to provide useful information to the faculty and university management to delegate a less burdensome scope of work and appropriate programs among lecturers (Tambi and Awang, 2019).

Abdullah et al., (2016) indicate that there are four dimensions of workplace happiness that have correlations with the behaviour of teachers' innovation which are teacher contribution, school climate, teacher belief and the involvement of teachers even though the dimension of teacher belief was found not have to any contact with the behavior of teacher innovation. However, Abdullah et al., (2016) stated that the elements of contribution, belief and confidence of teachers will affect the teachers' happiness in the workplace. Meanwhile, Ateerah and Lukman (2019) suggest that an Islamic perspective should be included in the indicator of happiness measurement to find the holistic measurement. An interesting finding shows that the environment where a person lives has significant impact on happiness which have correlated with workplace reported has negative and positive feeling on job performance (Ismail et al. 2013; Mushtaq \& Sajid 2013). Raop and Kadir (2011) indicate that gratitude have significant relationship to subjective happiness which emphasize the importance of gratitude produce happy and prosperous workers in the organizations. The applications of these values can be implemented through weekly or monthly motivation and spirituality programs.

Based on the previous studies, it can be concluded that there are several domains that affect the level of happiness in the organization where each domain has its own items that significantly affect individual happiness respectively. Most of the previous research focused on the organization, individual, social and family factors which can contribute to the lecturer happiness (Yang and Li, 2011, Abdul Ghani Kanesan et al., 2016 and Isa et al., 2019) and some of them have been studied based on the effect of inner element (Margaret et al., 2012 and Fouche and Van Der Vyver, 2017) and Islamic perspective as well (Ateerah and Lukman, 2019) that will help individuals to be resilient at work place. Thus, the holistic happiness and stress domains with significant and reliable items will be developed in this paper. The reliability and the validity of the items will be elaborated in the methodology section.

\section{Method}

This preliminary study was conducted using a quantitative approach by distributing the study instrument to the respondents. A total of 40 academicians were selected as respondents from three selected university which was under the clusters of Comprehensive University, Research University and Focus University. The definitions of the university clusters are shown in Table 1.

Table 1. The Indicator of University Clusters in Malaysia

\begin{tabular}{lll}
\hline No. $\quad$ Cluster of University & Indicator \\
\hline 1 & Comprehensive University & $\begin{array}{l}\text { This university provides various fields of programmes. The } \\
\text { admission ratio of postgraduates and undergraduates for the } \\
\text { research university is } 70: 50 .\end{array}$ \\
& The university is responsible for actively exploring new ideas, \\
& experimenting with innovative methods, and taking scientific \\
& initiatives in searching and developing knowledge. The admission \\
& ratio of postgraduates and undergraduate for the research university \\
& is 50:50. \\
& Focus University is an institution that provides attention to specific \\
& Focus University & The admission ratio of postgraduates and undergraduate for the \\
& research university is 50:50
\end{tabular}

According to Cooper and Schindler (2011), the appropriate number of respondents in the preliminary test was between 25 and 100 people. While Johanson and Brooks (2010) suggested that the minimum number of respondents for preliminary study for validating and developing a scale was 30 respondents. In addition, Timothy et al., (2013) added that the sample size determinations are highly sensitive to change in design assumptions. Therefore it is 
important to use a appropriate method in sampling. This research employed a self-developed questionnaire with four Likert scale as the research instrument.

The development of the items was done based on previous quantitative and qualitative research. The questionnaire was divided into two sections where section A measured the respondents' demographic information and section B measured the respondents' happiness and stress indicators. There were 66 items which consisted of three main constructs, including the organization (referring to university), social and individual. There were 33 items for happiness and 33 items for stress. Each construct contained three to four sub constructs and there were three items for in each sub constructs. Based on the results, only 1 item was considered to be dropped or needed improvement because the logit value was more than 1.40 logit and it showed that the item was confusing or did not meet the needs of the construct. Table 2 shows the details of MAHI construct items.

Table 2. The Details of MAHI Construct

\begin{tabular}{lllll}
\hline No. & Construct & Sub construct & $\begin{array}{l}\text { Number of item } \\
\text { (happiness) }\end{array}$ & $\begin{array}{l}\text { Number of item } \\
\text { (stress) }\end{array}$ \\
\hline 1 & University & Work load and Job Activities & Item A1-A3 & Item B34-B36 \\
& Work environment and Work & Item A4-A6 & Item B37-B39 \\
& Station & & \\
& Salary and compensation & Item A7-A9 & Item B40-B42 \\
& Leadership & Item A10-A12 & Item B43-B45 \\
& Job specification & Item A13-A15 & Item B46-B48 \\
& Family support & Item A16-A18 & Item B49-B51 \\
& Social & Friendship & Item A19-A21 & Item B52-B54 \\
& & Networking & Item A22-A24 & Item B55-B57 \\
& Religious & Item A25-A27 & Item B58-B60 \\
& Individual & Item A28-A30 & Item B61-B63 \\
& & Financial & Item A31-33 & Item B64-B66 \\
& Healthy and personal & $\mathbf{3 3}$ & $\mathbf{3 3}$ \\
& Sub Total (item) & $\mathbf{6 6}$ & \\
& Total (item) & &
\end{tabular}

The data were analyzed descriptively using the Statistical Package for Social Science (SPSS) program version 26 before being analyzed using Winstep version 3.69.1.11 software of the Rasch Measurement Model.

\section{Findings and Discussion}

This section discusses the validity and reliability of the items to measure the happiness level among the academicians in Malaysian University. The identification of reliable items will be used as an instrument to study the level of happiness and stress levels among Malaysian academicians.

The number of respondents of this pilot preliminary study was 40 academicians from three Malaysian public universities which were Comprehensive University, Focus University and Research University. The respondents were selected randomly. The questionnaire was distributed using Google forms where $52.5 \%(\mathrm{~N}=21)$ respondents were males while the rest of $47.5 \%(\mathrm{~N}=19)$ were females. The majority of the respondents were Malays (Muslims) which comprised 95\% ( $\mathrm{N}=38)$ and the rest were Buddhists that comprised 5.0\% $(\mathrm{N}=2)$. All the respondents were academicians from three different categories which involved 22.5\% ( $\mathrm{N}=9$ ) of Gred 41 - 45 which referred to lecturers, $67.5 \%(\mathrm{~N}=27)$ of Gred $51-54$ which referred to senior lecturers and $10 \%(\mathrm{~N}=4)$ of Professors. Meanwhile, most of the respondents were from the Focus University with 70\% ( $\mathrm{N}=29)$, followed by Research University 17.5\% ( $\mathrm{N}=7$ ) and Comprehensive University $12.5 \%(\mathrm{~N}=5)$. 


\subsection{Reliability and Separation Index}

Figure 1 shows the summary of the reliability and separation of person and item index obtained by analyzing the data using Winsteps. Reliability is a test to prove the quality of reproducibility of relative measure location. High reliability of person (which refer to the respondents) or item means that there is a high probability that the person or item estimated with high measure. Separation index is an index to classify the person's ability (person separation index) or item difficulty (item separation index). The instrument is considered good if the separation index for person and item are more than 2 because the person ability and item difficulty are varied (Bon \& Fox, 2007).

Based on the findings, the value of reliability for person is 0.83 and reliability for an item is 0.87 . Thus, $83 \%$ reliability on person and $87 \%$ reliability on items are at good levels and they are acceptable. Meanwhile, the value of separation index indicates the separation of item difficulty level is 2.57 and the separation of a person's ability to respond is 2.18. Separation index of both item and person show a good value because they are more than 2 .

As shown in Figure 1, the mean value for person index is 0.27 compared to the mean item which is 0.00 . This indicates that the respondents' ability to respond on the items was high and the level of difficulties is not in line with the respondent's ability. In the meantime, the standard deviation value shows that the distance between person is about 0.39 logit and the distance between items is about 0.30 logit.

The results of this preliminary study also show that the reliability value of Cronbach's Alpha $(\alpha)$ is 0.84 . This value reveals that the instrument used for in this pilot preliminary study has good items and is acceptable to a medium degree of consistency and can be used in actual research. Based on Rasch Measurement Model, Cronbach's Alpha value is possible and acceptable if it is between $0.71-0.99$ which is at good best level (71 \% - $99 \%)$ based on Bond \& Fox, (2007) as described in Table 3.

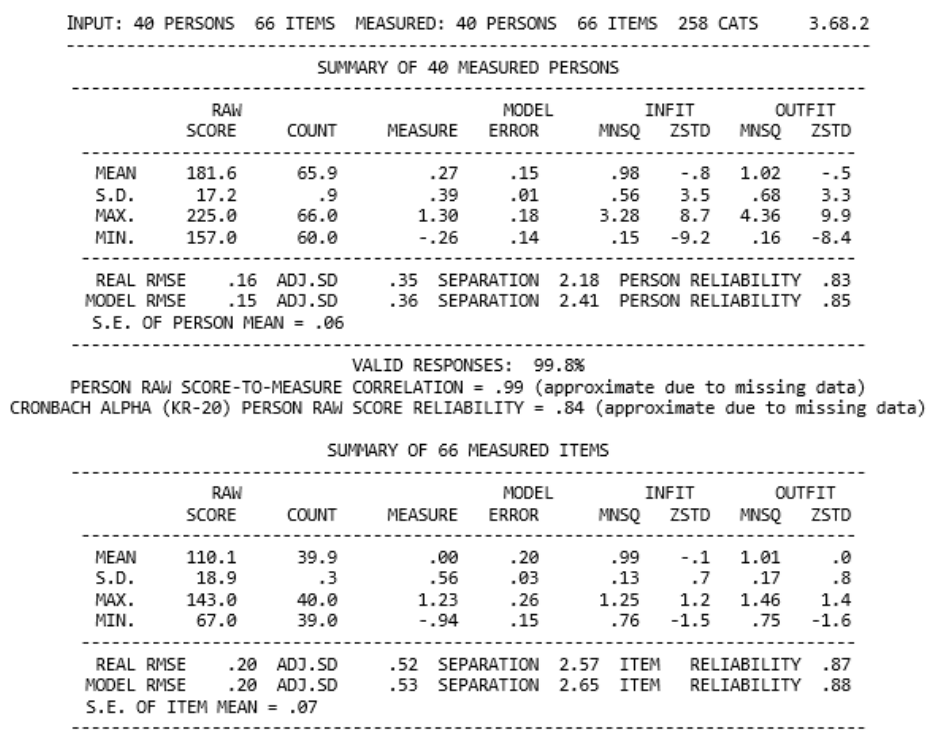

Figure 1. The Value of Reliability and Separation

Table 3. Cronbach's Alpha Values

\begin{tabular}{ll}
\hline $\begin{array}{l}\text { Score } \\
\text { Alpha-Cronbach }\end{array}$ & Reliability \\
\hline $0.9-1.0$ & Very Good and Effective with High Consistency Level \\
$0.7-0.8$ & Good and Acceptable \\
$0.6-0.7$ & Acceptable \\
$<0.6$ & Need an improvement \\
$<0.5$ & Need to drop \\
\hline
\end{tabular}




\subsection{Item Validity}

This study used Point Measure Correlation Coefficient (PTMEA), INFIT and OUTFIT mean square (MNSQ) to validate the questionnaire of the Malaysian Academician Happiness Index (MAHI). PTMEA correlation value is to test whether item polarity is moving or in line with the MAHI construct. If the value of PTMEA correlation is positive, it means that the items measure the construct that it wants to measure (Bond \& Fox, 2007). On the other hand, if the value is negative, the items developed do not measure the construct. These concepts are applied on MAHI. Therefore, the negative items need to be repaired or dropped because the items will not work to be answered where the respondents will find difficulties and will not be able to focus in answering the items provided.

Based on Figure 2, there are 8 items with negative values at of the PTMEA correlation with the index values -0.04 (item A30, A16, A32, A11, A7, A21, A6 and A12). This item which carries $12.12 \%$ out of 66 items could not measure the construct of MAHI. Therefore, this item (A30) needs to be repaired or dropped because the item does not address the question needed and can confuse the respondents or make it difficult for them to answer. A total of 8 out of 66 items in the range of index values in was -.17 to -.03. The data shows that these items which are A30, A16, A32, A11, A7, A21, A6, and A12 which could not measure the construct of MAHI. Therefore, these items need to be dropped or imrpoved.

Meanwhile, there are 29 items in the range of index values between .03 to .29 . The data shows that these items could measure the construct but the positive value is low and less than 0.30. It means that, all 29 items which are B35, B34, A18, A14, B66, A8, A19, A10, A31, A15, A28, A9, A27, A1, B38, A4, A33, A26, A23, A2, A3, A5, A20, B65, B37, B57, A13, B42, and A22 need attention and cleaning because they seem to be predictable for the respondents. However, the data shows that the low positive items are in line with the construct's needs and are able to measure the construct of MAHI without any conflict of answering to the respondents.

The rest of the items show positive value and are in range of 0.30 to 0.64 . About 29 out of 66 items have been identified to able to measure the construct of MAHI. This $43.9 \%$ of the items indicate that the items move in line with the constructs and are able to measure the construct without any conflict or confusion. All the positive values are A17, A24, A25, A29, B36, B39, B40, B41, B43, B44, B45, B46, B47, B48, B49, B50, B51, B52, B53, B54, B55, B56, B58, B59, B60, B61, B62, B63, and B64. 


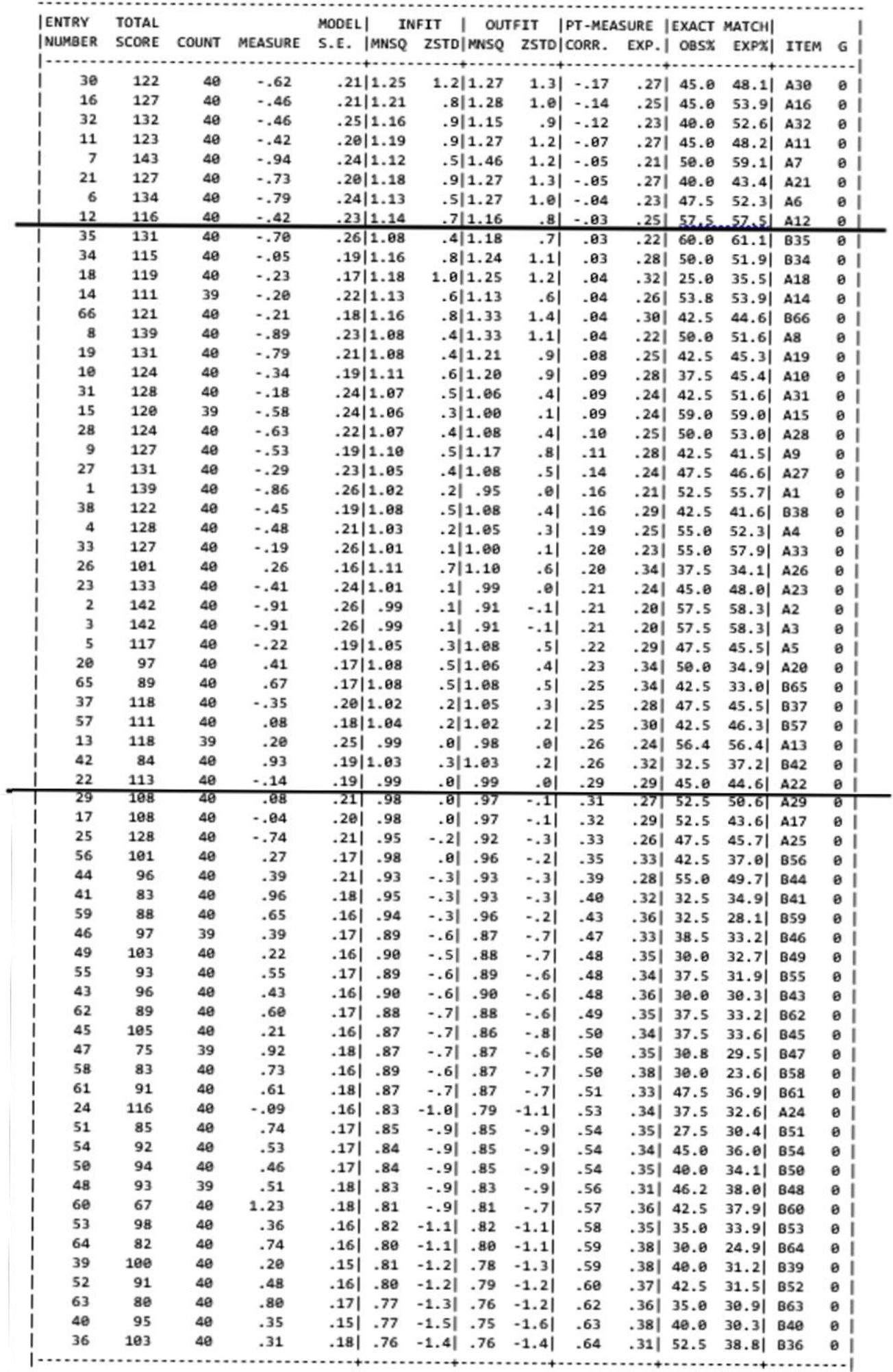

Figure 2. Value of Point Measure Correlation

\subsection{Fits Statistic}

Statistical analysis for item's suitability was carried out to identify the items with the value of mean-square (MNSQ) infit MNSQ and outfit MNSQ ranging from 0.6 to 1.4. The range between 0.6 and 1.4 is needed to ensure that the item being developed is appropriate to measure the construct (Bond \& Fox, 2007). If the value of MNSQ is more than 1.4 logit, it means that the item is confusing to the respondents. Meanwhile, if the value of MNSQ is less than 
0.6 logit, it shows that the item can be easily predicted by the respondents (Linacre, 2005). The value of MNSQ outfit index is influenced by outliers who could guess whether the item is right or wrong. Meanwhile, the value of MNSQ infit is influenced by the response pattern factor of respondents. Besides, the value of outfit ZSTD and infit ZSTD must be between the range of -2 to +2 (Bond \& Fox, 2007). According to Linacre (2005), if the values of outfit and infit MNSQ are accepted, the index of ZSTF can be ignored.

As stated in Figure 3, there is only one item (A7) with MNSQ value greater than 1.4 logit. The value of MNSQ outfit is 1.46 while the value of MNSQ infit is 1.12 which show that these items are misleading. Thus, item A7 can be considered for removal or refinement with an expert's advice. There are 65 items in MNSQ outfit and infit values which are within the fit range. These items are retained because they can measure the construct of MAHI. The $98.4 \%$ of these items are A1, A2, A3, A4, A5, A6, A8, A9, A10, A11, A12, A13, A14, A15, A16, A17, A18, A19, A20, A21, A22, A23, A24, A25, A26, A27, A28, A29, A30, A31, A32, A33, B1, B2, B3, B4, B5, B6, B7, B8, B9, B10, B11, B12, B13, B14, B15, B16, B17, B18, B19, B20, B21, B22, B23, B24, B25, B26, B27, 28, B29, B30, B31, B32 and B33. There is not any item with the MNSQ outfit and infit with less than 0.6 logit. This means that the questions are not predictable or very easy (Linacre, 2005) and the respondents will have to think carefully in answering these questions.

ITEM STATISTICS: MISFIT ORDER

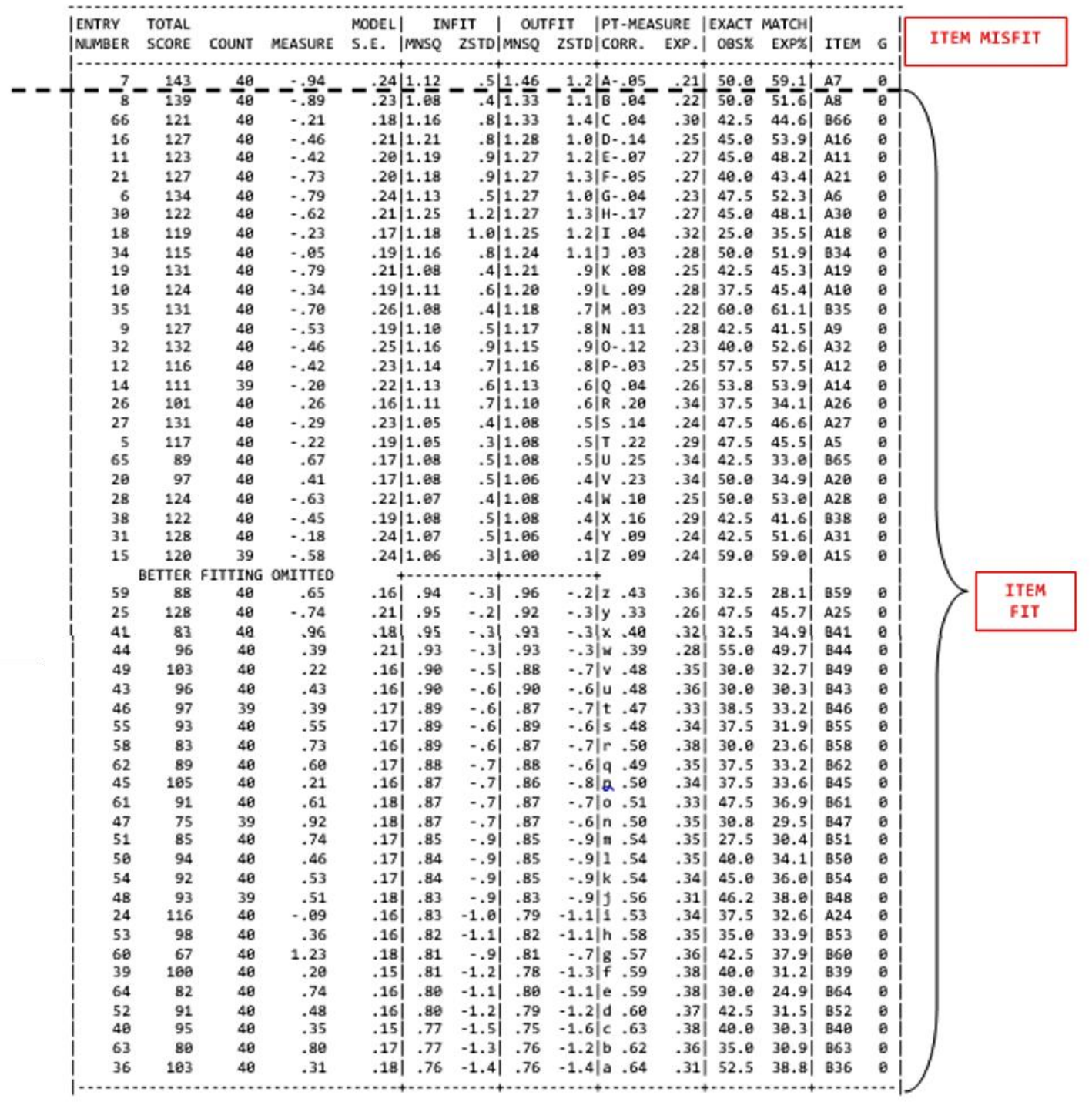

Figure 3. Fit Statistic Analysis 


\section{Conclusion}

Once the data is analyzed, the review of each item is done in accordance with the standard index and conditions that need to be followed in order to achieve the validity standards and the reliability of instruments based on the RASCH measurement model. The validity and reliability are very important aspects that should be considered in developing new instruments for a study. Based on the results of the preliminary study, there is only 1 item that do not meet the required analytical requirements and need to be eliminated because the value of MNSQ was 1.46 which is more than 1.4 logit.

Hence, based on the validity examination and reliability of this instrument, this instrument has the appropriate quality to be used by lecturers to gauge their level of happiness and stress. The implications of this analysis help the researchers in developing a Malaysian Academician Happiness Index (MAHI) in order to help produce a community of resilient lecturers.

\section{Limitation and Contribution of Study}

This study used the specific item indicator measurement from Islamic perspective which caused difficulty for the non-Muslims to answer the item. Therefore, an item was dropped and changed to general item but still in the context of the Islamic perspective indicator. The uniqueness of this study that could be seen was the development of item that represented the holistic approach indicator to measure the happiness and stress levels based on individual perspectives.

\section{Acknowledgment}

The authors would like to thank The Ministry of Education (MOE) for supporting this research through Fundamental Research Grant Scheme (FRGS/1/2019/SS03/UTHM/02/4) with Vot: K226, Universiti Tun Hussein Onn Malaysia (UTHM) and Universiti Kebangsaan Malaysia in research collaborators. We would like to show our gratitude to the respondents for their full support for this research.

\section{References}

Abdullah, A. G. K., Ali, A. J., Ling, Y. L. \& Ping, C. S. (2016). The Influence of Workplace Happiness Towards Teachers Innovative Behavior in Malaysia Education Organizations. Retrieved from http://dx.doi.org/10.18535/rajar/v2i4.02

Ateerah, A. R. \& Lukman, Z. M. (2019). Happiness Instrument Development. International Journal of Research and Innovation in Social Science, 3(4).

Aziz, R. (2014). Happiness Sustainable among Lecturers at the Malaysian Research University. (Doctoral of Education Thesis) Universiti Teknologi Malaysia. Skudai

Bond, T. \& Fox, C. (2007). Applying the Rasch Model: Fundamental Measurement in the Human Sciences (2nd). Mahwah, NJ: LEA. ISBN: 978-0-415-83341.

Cooper, D. R. \& Schindler, P. S. (2011). Business research methods (11th ed. ed.). New York: McGraw-Hill/Irwin. ISBN $\quad 1260127389,9781260127386$

Desa, A., Yusooff, F., Ibrahim, N. Abd Kadir, N. B. \& AbRahman, R. M. (2014). A Study of the Relationship and Influence of Personality on Job Stress among Academic Administrators at a University. Procedia - Social and Behavioral Sciences. Retrieved from https://doi.org/10.1016/j.sbspro.2013.12.711

Fisher, C.D. (2010). Happiness at Work. International Journal of Management Reviews, 12, 384-412. Retrieved from http://dx.doi.org/10.1111/1468-0297.00570

Fouche E., Rothmann S. S. \& Van der Vyver C. (2017). Antecedents and outcomes of meaningful work among school teachers. SA Journal of Industrial Psychology, 43(1), 1-10. Retrieved from http://dx.doi.org/10.4102/sajip.v43i0.1398

Hargreaves A. \& Fink D. (2006). Sustainable leadership. San Francisco, CA: Jossey-Bass. ISBN-13: 978-0787968380, ISBN-10: 0787968382

Henderson, N. \& Milstein, M. (1996). Resiliency in schools: Making it happen for children and educators. ISBN: 0-7619-4669-1

Hobfoll S. E., Johnson R. J., Ennis N. \& Jackson A. P. (2003). Resource loss, resource gain, and emotional outcomes among inner city women. Journal of personality and social psychology, 84(3), 632. Retrieved from http://dx.doi.org/10.1037/0022-3514.84.3.632 pmid:12635922 
Hoesni, S. M. \& Zakaria, S. M. (2019). Marital satisfaction and general happiness among urban Malays in Klang Valley. International Journal of Recent Technology and Engineering, 8(2S10), 97-100 http://dx.doi.org/10.35940/ijrte.B1016.0982S1019

Isa, K., Mat Jam, N. A., Wan Muda, W. H. N. \& Kadir, Shah, H. (2019). Crucial Personal Factors Leading to Stress in University. International Journal of Engineering and Advanced Technology, 9(1). 4305-4309

Ismail, R., Hafezi, M. H. \& Nor, R. M. (2014). The effect of demographic characteristic to quality of life and happiness in Malaysia. Research Journal of Applied Sciences, Engineering and Technology, 7(1), 198-205. Retrieved from https://doi:10.19026/rjaset.7.240

Jessica, V. W. \& Rob, F. P. (2019). Meaningful Work and Resilience Among Teachers: The Mediating Role of Work Engagement and Job Crafting. Research Article. Plos one. Retrieved from https://doi.org/10.1371/journal.pone.0222518

Johanson, G. \& Brooks, G. (2010). Initial Scale Development: Sample Size for Pilot Studies. Educational and Psychological Measurement, 70, 394-400. Retrieved from https://doi./10.1177/0013164409355692

Leahy, T. (2012). How Teachers Develop and Sustain Resilience in their Work. (Thesis of Doctor of Education). University of London. London

Liaison (2020). Fields required from institutions in All fields Academic teaching qualification. Retrieved from https://www.hesa.ac.uk/collection/c19025/a/actchqual

Linacre, J. M. (2005). A user's guide to WINSTEPS. [Computer Program]. Chicago: Winsteps.

Margaret, M., John, M. \& Vincent, M. (2012). Coping at university: The Role of Resilience, Emotional Intelligence, Age and Gender. Journal of Quantitative Psychology Research, 1, 1-6.

Maria, L. K. Scott, E. S. Lindsey, G. Jordan, N. \& Leisa, D. S. (2015). Navigating the Challenges of Academic Careers Obstacles, Shocks, and Facilitators of Professional Identification and Occupational Satisfaction among Academy of Management Academic Members. Career Report Summary. Retrieved from https://doi.org/10.5465/amle.2017.0391

Marten, S. (2019). The Challenges Facing Academic Staff in UK Universities. Retrieved from https://career-advice.jobs.ac.uk/academic/the-challenges-facing-academic-staff-in-uk-universities/

Musikanski, L. (2015). Measuring Happiness to Guide Public Policy Making: A Survey of Instruments and Policy Initiatives. Journal of Social Change, 7(1), 39-55. Retrieved from https://doi/10.5590/josc.2015.07.1.04

Ramlee, N. (2015). Stress level among the lecturers of Vocational College in Johor. (Thesis of Master Education). Universiti Tun Hussein Onn Malaysia. Batu Pahat.

Raop, N. A. \& Kadir, N. B. Y. A. (2011). The Sense of Life, Grateful and the Relationship with the Employee Happiness. Journal of Social Sciences and Humanities, 6(2), 349-358.

Safian, M. T. M. (2007). The Impact of Health on Productivity among the Lecturers of the Teachers College. (Thesis of Master Education). Universiti Sains Malaysia. Pulau Pinang

Seligman, M.E.P (2002). Authentic Happiness: Using the New Positive Psychology to Realize Your Potentialfor Lasting Fulfillment. New York : Free Press.

Seligman. (2005). Authentic Happiness. UK: New York.

Tambi, N. \& Awang, S. Z. (2019). The Relationship between Work and Emotional Intelligence Stress on Job Satisfaction among Lecturer in the Faculty of Social Sciences and Humanities, Universiti Kebangsaan Malaysia. e-BANGI Journal, 16, 5(1), 19.

Tharek, M. (2011). The Universiti Teknologi Malaysia Lecturer's Work Stress and Satisfaction. (Thesis of Master). Skudai.

Timothy, C., Ursula, B. \& Ulrich, M. (2013). Sample Size Determinations in Original Research Protocols for Randomised Clinical Trials. Submitted to UK Research Ethics Committees: Review. Institut für Medizinische Informationsverarbeitung, Biometrie und Epidemiologie, Faculty of Medicine, Ludwig-Maximilians University, Munich, Germany

Windle G. (2011). What is resilience? A Review and Concept Analysis. Reviews in Clinical Gerontology, 21(2), 152-169. Retrieved from https://doi.org/10.1017/S0959259810000420 
Wulandari, S. \& Widyastuti, A. (2004). The Factor Contributing to Happiness at the Work place. Jurnal Psikologi, 103

Yang, X. X. X., Li, X., Liang, Y., Wang, L., Wu, H. \& Lin, X. (2011). Evaluation on reliability and validity of ZBI in Caregivers of Mental Illness Patients. Occupation and Health, 27(19), 2229-2230.

Zafir, M.M. \& Fazilah, M. H. (2010). Stress at the Work place: How the Ergonomic Factors Minimize it? The 5th National Human Resource Management Conference 2010, 642-657. Universiti Utara Malaysia. Sintok. 